\title{
J-sternotomy incision for aortic valve surgery: an initial experience of a tertiary care hospital
}

\author{
Korhan Erkanlı, Burak Onan, Ünal Aydın, Ersin Kadiroğulları, Onur Şen, Mehmet Yeniterzi, İhsan Bakır \\ Received: February 02, 2016 Accepted: March 14, 2016 Published online: July 21, 2016
}

\begin{abstract}
Objectives: This study aims to present our single-center experience of an aortic valve replacement using a minimally invasive J-sternotomy incision and to compare the early clinical outcomes of these procedures with a median sternotomy.

Patients and methods: Between January 2014 and May 2015, 38 patients underwent isolated aortic valve replacement operations using a minimally invasive or a conventional sternotomy. A J-sternotomy (group JS) incision was used on 18 patients (12 males, 6 females; mean age $57.0 \pm 17.9$ years; range 19 to 62 years), whereas a median sternotomy (group MS) incision was performed on 20 patients (13 males, 7 females; mean age $57.4 \pm 16.3$ years; range 22 to 65 years). Preoperative characteristics, perioperative data and early outcomes were compared. Patient selection techniques, the surgical approach and our experience during the procedures were presented.

Results: No mortality developed. The types $(\mathrm{p}=0.36)$ and dimensions $(\mathrm{p}=0.99)$ of implanted aortic valves were similar between the groups. There was no significant difference between the JS and MS groups in terms of cross-clamp $(68.4 \pm 30.1$ vs. $64.7 \pm 29.9$ minutes, $\mathrm{p}=0.70)$ and cardiopulmonary bypass time $(112.3 \pm 43.1$ vs. $94.8 \pm 43.8$ minutes, $\mathrm{p}=0.22)$. In the group JS, conversion to full sternotomy was needed in one patient due to poor surgical exposure. The lengths of intensive care unit $[1.7 \pm 1.7$ vs $2.2 \pm 1.2$ days, ( $\mathrm{p}=0.33)]$ and hospital [7.1 \pm 2.7 vs $7.2 \pm 1.2$ days, $(\mathrm{p}=0.66)$ ] stays were similar between the groups. A mediastinal exploration due to bleeding was performed using a full sternotomy in two patients (11.2\%) from group JS. There was no significant difference in postoperative complications.

Conclusion: Since it is minimally invasive for aortic valve replacement using a J-sternotomy incision is a safe and reproducible procedure. The use of a minimally invasive aortic valve replacement technique does not lead to a higher incidence of postoperative complications and associated mortality.
\end{abstract}

Keywords: Aortic valve replacement; J-sternotomy; minimally invasive surgery.

Minimally invasive techniques have been used to perform aortic valve procedures to reduce surgical trauma for more than a decade. After the original description of minimally invasive aortic valve replacement (AVR) with a right thoracotomy in the early 1990s, this approach, with a number of different variations, remains a viable alternative to a conventional sternotomy. ${ }^{[1-7]}$ Despite the more common use of the parasternal and transverse approaches in the initial reports, upper hemisternotomy and right anterior minithoracotomy are frequently used in the current surgical practice. ${ }^{[3-5]}$ The more frequent use of sutureless valves along with growing expertise may be expected to result in the more frequent use of minimally invasive approaches for AVR. ${ }^{[8,9]}$ Clinically, surgery performed using smaller incisions offer a number of advantages such as reduced postoperative pain and surgical trauma..$^{[3-5]}$ Also, a minimally invasive AVR appears to be superior to aortic valve surgery with a conventional sternotomy in terms of less bleeding, shorter ventilation and a reduced length of time in the intensive care unit and a shorter hospital stay. ${ }^{[1-7]}$

Since we have only recently introduced minimally invasive AVR procedures in our center, we decided to share our clinical experience on AVR with a $\mathrm{J}$-sternotomy during a one-year period in comparison with the conventional AVR in terms of clinical outcomes, early morbidity and early challenges.

\section{PATIENTS AND METHODS}

This was a retrospective analysis of prospectively collected data from a single center series of AVR using either a partial (upper J-sternotomy) or complete

Department of Cardiovascular Surgery, İstanbul Mehmet Akif Ersoy Cardiovascular Surgery Training and Research Hospital, İstanbul, Turkey

Corresponding author: Burak Onan, MD. İstanbul Mehmet Akif Ersoy Gögüs Kalp ve Damar Cerrahisi Eğitim ve Araștırma Hastanesi, Kalp ve Damar Cerrahisi Kliniği, 34303 Küçükçekmece, İstanbul, Turkey.

Tel: +90 553 - 6223878 e-mail: burakonan@hotmail.com 
sternotomy approach between January 2014 and May 2015. The Institutional ethical committee approved this study. A written informed consent was obtained from each patient. The study was conducted in accordance with the principles of the Declaration of Helsinki. Data collection was obtained using patient records and the department database. During the study period, 45 consecutive patients underwent isolated AVR procedures. Thirty-eight patients undergoing AVR were included in the study. The patients were divided into two groups; 18 were operated on using a partial upper J mini-sternotomy (group JS; 12 males, 6 females; mean age $57.0 \pm 17.9$ years; range 19 to 62 years) and 20 using a conventional median sternotomy (group MS; 13 males, 7 females; mean age $57.4 \pm 16.3$ years; range 22 to 65 years). Operations were all performed by consultant surgeons. The decision about the choice of procedure type was based entirely on the patient's general status, anatomical considerations and at the discretion of the attending surgeon. Exclusion criteria were the presence of infective endocarditis or endocarditis requiring emergent care in seven patients. A chest wall deformity such as a pectus excavatum, history of radiation exposure, previous cardiothoracic surgery, combined procedures and intervention on the aortic root or ascending aorta, morbid obesity and concomitant cardiac pathologies requiring surgical repair were the other exclusion criteria.

Procedures were performed using the same technique in each group and performed by the same surgical team. The surgical technique was described previously. ${ }^{[3,4]}$ After the induction of general anesthesia, in the minimally invasive group (group JS), a 6-8 cm midline skin incision was made beginning $2 \mathrm{~cm}$ above the angle of Louis until 4 to $6 \mathrm{~cm}$ below the angle. The sternotomy was incised with the oscillating saw down until the intercostal space between the second and fourth depending on the topographic relationships of the anatomic structures (Figure 1). After the retractors were placed, the pericardium was accessed. Aortic cannulation was directly performed through the ascending aorta. A single femoral vein cannulation was performed percutaneously through the right femoral vein (Medtronic Biomedicus femoral 21 or 24 Fr venous cannula-Minneapolis, USA). In patients with inadequate venous flow, venous drainage was supported by selective cannulation of the vena cava superior. Figure 2 shows the intraoperative exposure of a patient, who underwent an AVR with J-sternotomy. In the group MS, a conventional AVR was performed via a full median sternotomy applying double stage venous cannulas with the same methods of myocardial protection.

An intraoperative transesophageal echocardiography was used routinely to assess cardiac function, evaluate surgical results and confirm the de-airing process. There was also a routine examination during peripheral cannulation. Myocardial protection of both groups was achieved with systemic hypothermia $\left(28-32{ }^{\circ} \mathrm{C}\right)$, and antegrade isothermic blood cardioplegia. Cardioplegia doses were selectively maintained through coronary ostia every 20 minutes. The left ventricular vent (a)

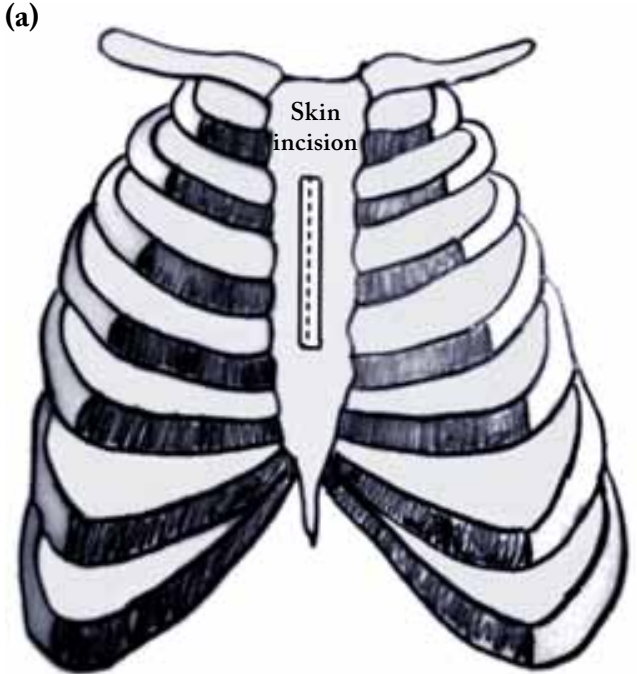

(b)

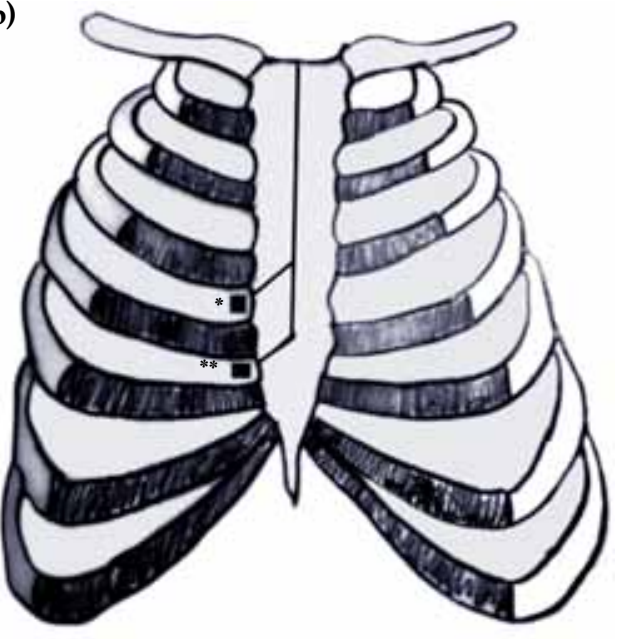

Figure 1. Surgical incisions. (a) Skin incision and (b) partial sternotomy incision.

* Third intercostal space; ${ }^{* *}$ Fourth intercostal space. 


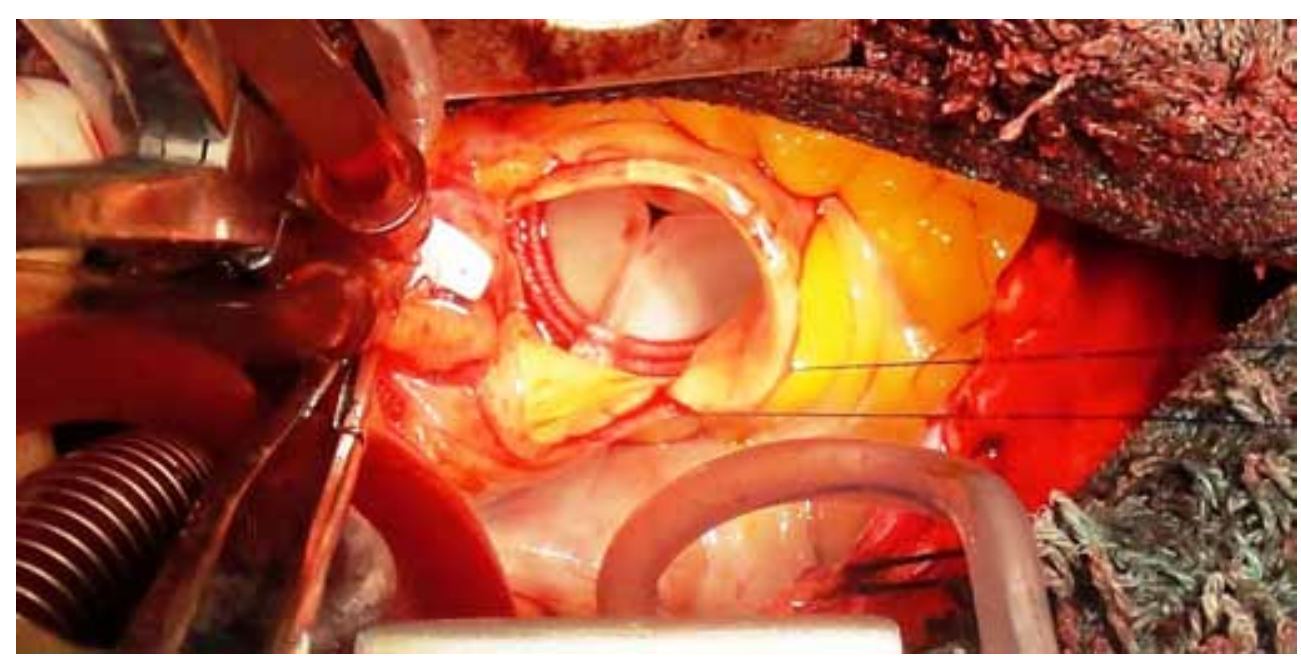

Figure 2. Surgical exposure of the aortic valve through an upper J-sternotomy after implantation of a bioprosthetic aortic valve.

was provided through the right upper pulmonary vein. Carbon dioxide insufflation was used in all procedures. At the end of each procedure, a single ventricular epicardial pacemaker was placed before aortic declamping. A single $32 \mathrm{~F}$ chest tube was placed immediately after cardiac arrest and removed 48 hours after the operation.

Clinical, operative and outcome data was prospectively collected in a computerized database.
All patients had eight weeks of follow-up care after being discharged from the hospital. During this time, operative variables and postoperative complications were recorded. Follow-up visits took place in our unit.

\section{Statistical analysis}

NCSS (Number Cruncher Statistical System) 2007 Statistical Software (Utah, USA) pack was used for

\begin{tabular}{|c|c|c|c|c|c|c|c|}
\hline \multicolumn{8}{|c|}{$\begin{array}{r}\text { Table } \mathbf{1} \\
\text { Demographic characteristics, aortic valve p }\end{array}$} \\
\hline & \multicolumn{3}{|c|}{ Group JS ( $n=18)$} & \multicolumn{3}{|c|}{ Group MS (n=20) } & \multirow[b]{2}{*}{$p$} \\
\hline & $\mathrm{n}$ & $\%$ & Mean \pm SD & $\mathrm{n}$ & $\%$ & Mean \pm SD & \\
\hline Age (years) & & & $57.0 \pm 17.9$ & & & $57.4 \pm 16.3$ & 0.93 \\
\hline \multicolumn{8}{|l|}{ Gender } \\
\hline Female & 6 & 33.3 & & 7 & 35 & & 0.91 \\
\hline New York Heart Association class & & & $2.1 \pm 1.3$ & & & $2.1 \pm 1.5$ & 0.56 \\
\hline Obesity $(\mathrm{BMI} \geq 30)$ & & & $26.3 \pm 3.8$ & & & $32.6 \pm 18.5$ & 0.16 \\
\hline Hypertension & 9 & 50 & & 7 & 35 & & 0.35 \\
\hline Obstructive lung disease & 7 & 38.9 & & 8 & 40 & & 0.94 \\
\hline Diabetes & 6 & 33.3 & & 5 & 25 & & 0.57 \\
\hline Renal failure & 0 & 0 & & 1 & 5 & & 0.33 \\
\hline TIA/CVA & 1 & 5.6 & & 0 & 0 & & 0.28 \\
\hline Cigarette use & 13 & 72.2 & & 12 & 60 & & 0.42 \\
\hline Atrial fibrillation & 1 & 5.6 & & 1 & 5 & & 0.93 \\
\hline Ejection fraction (\%) & & & $60.5 \pm 4.8$ & & & $57.8 \pm 9.4$ & 0.28 \\
\hline \multicolumn{8}{|l|}{ Aortic valve pathology } \\
\hline Aortic failure & 3 & 16.7 & & 4 & 16 & & \\
\hline Aortic stenosis & 7 & 38.9 & & 5 & 25 & & 0.65 \\
\hline Mixed & 8 & 44.4 & & 11 & 55 & & \\
\hline
\end{tabular}


statistical analyses. For data analysis, in addition to descriptive statistical methods (mean, standard deviation), an independent t-test was used for the pairwise comparison of the groups. Preoperative and postoperative comparisons were performed using the paired t-test, and chi-square and Fisher's exact tests were used for the comparison of qualitative data. The level of significance was set at a $p$ value of less than 0.05 .

\section{RESULTS}

The preoperative demographic data of the patients is shown in Table 1. Members of each group were similar in terms of age, sex, New York Heart Association functional class, left ventricular ejection fraction, obesity (body mass index above 30), hypertension, diabetes, obstructive pulmonary disease, renal failure, previous ischemic cerebral event, atrial fibrillation (AF) and history of smoking. The incidence of aortic valve pathologies was also similar between the groups $(\mathrm{p}=0.65)$. In the group JS and MS, aortic regurgitation presented in three patients (16.7\%) and four patients (16\%), aortic stenosis in seven patients (38.9\%) and five patients (25\%) and mixed aortic pathology presented in eight patients (44.4\%) and 11 patients (55\%), respectively.
Operative data is presented in Table 2. There was no significant difference between the JS and MS groups in terms of aortic cross-clamp $(68.4 \pm 30.1$ vs. $64.7 \pm 29.9$ minutes, $\mathrm{p}=0.70$ ) and cardiopulmonary bypass $(112.3 \pm 43.1$ vs. $94.8 \pm 43.8$ minutes, $\mathrm{p}=0.22)$ times. In the JS group, conversion to full sternotomy was made in one patient due to inadequate intraoperative exposure. The types of implanted aortic valves $(p=0.36)$ and valve dimensions $(p=0.99)$ were similar between the groups. In the JS group, nine (50\%) mechanical and nine $(50 \%)$ biological aortic valves were implanted. Of biological valves, eight of them were of the suturelesstype. In the group MS, 10 (50\%) mechanical and $10(50 \%)$ biological aortic valves were implanted. Of biological valves, six of them were sutureless. Most patients had an aortic valve size of 21 or above in the group JS, as in the group MS ( $\mathrm{p}=0.99)$. In each group, only three patients had size 19 aortic valves implanted. No procedure related morbidity developed. All operations were completed uneventfully.

The postoperative data for the patients is shown in Table 3. No mortality developed in either group. The length of stay in the intensive care unit $(1.7 \pm 1.7$ vs $2.2 \pm 1.2$ days $(\mathrm{p}=0.33)$ and hospital stay $(7.1 \pm 2.7$ vs $7.2 \pm 1.2$ days $(\mathrm{p}=0.66)$ were statistically similar between patients with J-sternotomy and median sternotomy. The incidences of postoperative AF were similar

\begin{tabular}{|c|c|c|c|c|c|c|c|}
\hline \multicolumn{8}{|c|}{$\begin{array}{c}\text { Table } 2 \\
\text { Operative data }\end{array}$} \\
\hline & \multicolumn{3}{|c|}{ Group JS (n=18) } & \multicolumn{3}{|c|}{ Group MS (n=20) } & \multirow[b]{2}{*}{$p$} \\
\hline & $\mathrm{n}$ & $\%$ & MeanะSD & $\mathrm{n}$ & $\%$ & Mean \pm SD & \\
\hline Cross-clamp time & & & $68.4 \pm 30.1$ & & & $64.7 \pm 29.9$ & 0.70 \\
\hline Cardiopulmonary bypass time & & & $112.3 \pm 43.1$ & & & $94.8 \pm 43.8$ & 0.22 \\
\hline Conversion to full sternotomy & 1 & 5.6 & & - & - & & \\
\hline Aortic valve type & & & & & & & 0.36 \\
\hline Mechanical & 9 & 50 & & 10 & 50 & & \\
\hline Biological & 9 & 50 & & 10 & 50 & & \\
\hline With stent & 1 & 5.6 & & 4 & 20 & & \\
\hline Sutureless & 8 & 44.4 & & 6 & 30 & & \\
\hline Type of sutureless valve & & & & & & & 0.63 \\
\hline Medtronic enable & 2 & 11.2 & & 1 & 5 & & \\
\hline Perceval & 1 & 5.6 & & 1 & 5 & & \\
\hline Edwards intuity & 5 & 27.8 & & 3 & 15 & & \\
\hline Aortic valve no & & & & & & & 0.99 \\
\hline 19 & 3 & 16.7 & & 3 & 15 & & \\
\hline 21 & 8 & 44.4 & & 10 & 50 & & \\
\hline 23 & 4 & 22.2 & & 4 & 20 & & \\
\hline 25 & 3 & 16.7 & & 3 & 15 & & \\
\hline
\end{tabular}




\begin{tabular}{|c|c|c|c|c|c|c|c|}
\hline \multicolumn{8}{|c|}{$\begin{array}{c}\text { Table } 3 \\
\text { Postoperative data }\end{array}$} \\
\hline & \multicolumn{3}{|c|}{ Group JS ( $n=18)$} & \multicolumn{3}{|c|}{ Group MS $(n=20)$} & \multirow[b]{2}{*}{$p$} \\
\hline & $\mathrm{n}$ & $\%$ & Mean \pm SD & $\mathrm{n}$ & $\%$ & Mean \pm SD & \\
\hline Mortality & 0 & 0 & & 0 & 0 & & \\
\hline Intensive care unit stay (day) & & & $1.7 \pm 1.7$ & & & $2.2 \pm 1.2$ & 0.33 \\
\hline Hospital stay (day) & & & $7.1 \pm 2.7$ & & & $7.2 \pm 1.2$ & 0.66 \\
\hline New-onset atrial fibrillation & 2 & 11.2 & & 4 & 20 & & 0.45 \\
\hline Need for blood products (unit/patient) & & & $2.7 \pm 1.7$ & & & $3.3 \pm 2.3$ & 0.39 \\
\hline TIA/CVA & 1 & 5.6 & & 2 & 10 & & 0.61 \\
\hline Acute renal failure & 1 & 5.6 & & 0 & 0 & & \\
\hline Prolonged ventilation $(>48 \mathrm{~h})$ & 2 & 11.2 & & 4 & 20 & & 0.45 \\
\hline Pneumonia & 1 & 5.6 & & 1 & 5 & & 0.93 \\
\hline Pleural effusion & 1 & 5.6 & & 2 & 10 & & 0.61 \\
\hline Re-exploration for bleeding & 2 & 11.2 & & 3 & 15 & & 0.93 \\
\hline Mediastinal drainage & & & $390.5 \pm 232.2$ & & & $430.2 \pm 265.2$ & 0.63 \\
\hline Reoperation & 1 & 5.6 & & 0 & 0 & & \\
\hline Sternal wound site infection & 2 & 11.2 & & 1 & 5 & & 0.28 \\
\hline Transient pacemaker & 0 & 0 & & 1 & 5 & & \\
\hline Intra-aortic balloon pump & 0 & 0 & & 0 & 0 & & \\
\hline
\end{tabular}

between the groups $(p=0.45)$. There were no significant differences in new-onset renal failure (creatinine above $1.5 \mathrm{mg} / \mathrm{dL}$ ), respiratory problems, sternal wound infection, need for a temporary pacemaker, and all other characteristics were comparable between the groups. There were not any groin complications associated with femoral cannulation. The amount of mediastinal drainage was similar between the groups. However, a mediastinal exploration due to bleeding was performed using a full sternotomy on two patients (11.2\%) from the group JS. The bleeding site was in a branch of the right internal thoracic artery in one patient and, the other patient bled from the aortotomy incision In the group JS, one (5.6\%) patient with a sutureless biological AVR had severe paravalvular leakage during the early follow-up period and a mechanical valve replacement was performed on postoperative day 3 through a full conventional sternotomy.

\section{DISCUSSION}

In this study, our initial experience showed that AVR using J-sternotomy incision is a safe and reproducible procedure. The use of a minimally invasive AVR technique does not lead to a higher incidence of postoperative complications and associated mortality. Because this was an initial experience, the duration of the procedures in the J-sternotomy approach was relatively longer in the first cases, compared to the sternotomy approach. As our technical experience increased, we observed the feasibility and safety of the J-sternotomy approach. Exposure of the surgical field and aortic valve was satisfactory in the J-sternotomy cases. The clinical results of this approach were similar to the conventional sternotomy approach. There were no significant differences in postoperative complications. No mortality was observed.

In the current era, right anterior thoracotomy, median mini-sternotomy ( $\mathrm{J}, \mathrm{L}$, reverse $\mathrm{C}$ and $\mathrm{T}$ ) and percutaneous aortic valve implantation represent the most preferred minimally invasive AVR approaches by cardiovascular surgeons. ${ }^{[1-10]}$ The technique utilized in our unit, i.e. J-sternotomy is also known as an upper hemisternotomy and is a routinely performed minimally invasive AVR technique in many centers. ${ }^{[3-5]}$ Previous studies of minimally access and conventional median sternotomy approaches for AVR have showed comparable early mortality and postoperative complications. ${ }^{[1-7]}$ In our study, the two groups were not only comparable in terms of cross-clamp and CPB time, but also in terms of the hospital and ICU stay. In this small series, mortality was not observed.

In minimally invasive procedures, especially in the beginning of a learning curve, patient selection 
is paramount for AVR using J-sternotomy incision. Procedures should be performed in isolated pathologies and therefore a detailed clinical assessment should be made preoperatively including biochemical tests, chest graphics, echocardiography, coronary angiography, computed tomography (CT) of the thoracic cavity and even peripheral vessels for $\mathrm{CPB} \cdot{ }^{[3-5]}$ In this study, the decision about the choice of procedure type was entirely based on the patient's general status, anatomical considerations and at the discretion of the attending surgeon. Exclusion criteria were the presence of infective endocarditis or endocarditis requiring emergent care, combined procedures and intervention on the aortic root or ascending aorta. Patients with concomitant coronary disease, valve pathology or poor ventricular function were also excluded. Additionally, the chest anatomy was examined before the operation. Because we made an upper partial sternotomy, any deformity of the sternum, ribs or vertebra might be a limitation on the feasibility of the procedure and complicate surgical exposure.

In minimally invasive procedures, surgical exposure is the most important step for the feasibility of the operation, as done in conventional cases. Nevertheless, some technical tips and pitfalls are paramount for improving the experience of the surgeon especially in the learning curve. In the initial cases, operation times can be longer than the expected time of the operation. This can relate to limited exposure of the surgical field, manipulation of instruments in a relatively small area and the difficulty of synchronizing the surgeon with the assistant surgeon in a limited space towards the aortic valve.

In a meta-analysis by Murtuza et al. ${ }^{[11]}$ reviewing minimally invasive AVR procedures, although longer cross-clamp and CPB times were observed, a positive effect on the duration of hospital and ICU stay has been reported. Actually, in our initial patients, surgical set-up, exposure after skin incision and valve procedures took a relatively longer time. We believe that, with increased experience, the duration of the surgery may be shortened, leading to shorter hospital and ICU stays in our unit as well. Again, recent studies have suggested that an improvement in these parameters, i.e. length of hospital and ICU stay, may be likely with the development of sutureless valves or valves that can be replaced quickly. ${ }^{[12]}$ Similarly, reports on the intermediate- and late-term outcomes with sutureless valves may increase their use, facilitate valve replacement, and shorten the duration of surgery in minimally invasive procedures with limited surgical exposure.

The operation technique has been described previously, ${ }^{[3-5]}$ but some points need to be clarified. Technically, the sternotomy incision is a J-shape and goes down to the third or fourth intercostal space on the right. The decision of which intercostal space use is made using a chest X-ray or CT image to define the level of the aortic annulus. One of the most important details is to avoid an injury to internal thoracic artery on the right side. Then, the sternum is opened. Pericardial suspension sutures are placed before stabilizing the sternal retractor. Pericardial sutures are placed deep enough and, with a gentle force, they are fixed on the skin. By this way, the aorta and the annulus come towards the surgeon. After starting $\mathrm{CPB}$, a mediastinal chest tube is placed and carbon dioxide insufflation starts using this tube. This is helpful during de-airing maneuvers and while weaning from CPB. At this stage, an additional cannula to superior vena cava or left pulmonary vein can be placed. Transesophageal echocardiography is an essential component of the procedures because the heart is partially seen macroscopically.

A J-sternotomy can be accomplished with the use of widely available surgical material, rendering this technique a more feasible approach. However, even in centers routinely performing J-sternotomy for many years, the reported rates of transition to conventional sternotomy to prevent potential complications vary between 1.8 and $4 \% .{ }^{[13]}$ The reasons for such transition are generally categorized into two groups: early and late. ${ }^{[5]}$ The reasons for early transition include porcelain aorta and inadequate surgical exposure, while late transitions are generally due to dissection, bleeding at the cannulation site (internal iliac vein, jugular vein, coronary sinus), bleeding at sites other than the cannulation site (left atrium, aorta), persistent ventricular fibrillation, and formation of thrombi within the left ventricle. In our preliminary series of 18 patients, a need for transition to full median sternotomy occurred in only one patient due to inadequate exposure. This was made to perform a safer and effective removal of annular calcification. In the postoperative period, mediastinal exploration due to bleeding was performed using a full sternotomy in two patients (11.2\%) from group JS. The bleeding site was a branch of the right internal thoracic artery in one patient and, in the other patient, was at the aortotomy incision that was controlled primarily. 
The cannulation site in minimally invasive AVR procedures has an influence on the occurrence of neurological complications and on the need for transition to open surgery. Initially, femoral artery cannulation was more frequently used in minimally invasive AVR, with a subsequent increase in the use of central aortic cannulation through the J-sternotomy incision. ${ }^{[14]}$ The latter approach has been reported to be associated with a lower incidence of neurological complications. Again, another alternative to femoral vein cannulation, i.e. cannulation through the appendix of the right atrium, is being used increasingly. ${ }^{[15]}$ Similarly, although we performed femoral artery cannulation in our initial cases, now we routinely perform central aortic cannulation, so we can provide a better venous drainage through superior vena cava cannulation in cases with inadequate drainage after a femoral vein cannulation.

In the literature, previous studies have shown that AVR procedures using J-sternotomy have similar clinical results with conventional procedures through median sternotomy. ${ }^{[3-7]}$ Postoperative complications such as AF, bleeding, re-exploration, renal failure or the pericardial effusion rate have been reported to be comparable to conventional operations, as done in our study. Actually, some of the reported superiorities of J-sternotomy include early mobilization, less pain and a decreased hospital stay. ${ }^{[3-7]}$ We believe that with increased experience using the J-sternotomy approach, the difference between the two methods would be in favor of limited incision, rather than a full sternotomy approach. Our results could be a result of the small number of patients in the groups as well as the initial experience of our center.

The only consideration for the surgeon is the exposure. After establishing an adequate control of the surgical field and aortic root, we experienced that removal of the valve or calcifications as well as placement of sutures is feasible. With this approach, some centers routinely perform aortic valve, root and ascending aorta procedures as well as even proximal aortic arch reconstruction. ${ }^{[3-5]}$

The reported risk of postoperative neurological complications in patients undergoing minimally invasive AVR is $2-3 \%{ }^{[3]}$ Methods such as carbondioxide insufflation into the surgical field to prevent air embolisms as well as the use of antegrade root vent and transesophageal echocardiography are important measures to prevent such neurological complications.
Another factor associated with increased risk of neurological complications is represented with newonset AF. In patients undergoing minimally invasive AVR, an incidence of up to $34 \%$ has been reported for new-onset AF. ${ }^{[16]}$ In our study, one patient in the J-sternotomy group had left hemiparesis during the early postoperative period and it was medically treated. Again, two patients (11.2\%) had new onset AF postoperatively. However, the patient with the neurological complications had no AF.

There are certain conditions limiting the use of minimally invasive AVR. Some surgeons do not perform mini-incisions in patients with severe aortic regurgitation due to left ventricular distention. Nevertheless, surgical expertise clearly correlates with the success of these procedures. ${ }^{[17-19]}$ Venting of the left ventricle can be performed through a left superior pulmonary vein cannulation. This is possible immediately after starting $\mathrm{CPB}$ through a limited exposure. And also, selective delivery of antegrade cardioplegia is feasible after exposing the aortic root. Alternatively, in some centers, specially designed percutaneous catheters are inserted through the right internal jugular vein and coronary sinus under transesophageal echocardiography guidance to deliver cardioplegia solutions. ${ }^{[3-5]}$ After our initial experience with minimally invasive surgery with this group of patients, our target is to gain further experience with this approach as to expand its use to include ascending aorta interventions.

Due to limited surgical exposure, minimally invasive AVR is a challenging and stressful procedure for surgeons inexperienced with this technique. Also, minimally invasive surgery involves more technical details. However, with expertise, these challenges can be overcome and in appropriately selected patients, minimally invasive AVR can be accomplished as easily as the conventional methods. Furthermore, several centers reported the use of this approach even for ascending aorta surgery and reoperations after adequate experience had been gained. ${ }^{[3-6]}$

The limitations of our study include the small sample size, absence of randomization and the short duration of follow-up. This study was a retrospective analysis of prospectively collected data. The decision to perform AVR in each case was made by reviewing the general patient status, anatomical considerations and at the discretion of the attending surgeon. There 
may be a limitation on preoperative selection of patients who were candidates for AVR.

In conclusion, a minimally invasive procedure for aortic valve replacement using a J-sternotomy incision is a safe and reproducible procedure. The use of a minimally invasive aortic valve replacement technique does not lead to a higher incidence of postoperative complications and mortality. We believe that this procedure can be increasingly used in cardiac surgery to decrease surgical trauma and associated complications.

\section{Declaration of conflicting interests}

The authors declared no conflicts of interest with respect to the authorship and/or publication of this article.

\section{Funding}

The authors received no financial support for the research and/or authorship of this article.

\section{REFERENCES}

1. Rao PN, Kumar AS. Aortic valve replacement through right thoracotomy. Tex Heart Inst J 1993;20:307-8.

2. von Segesser LK, Westaby S, Pomar J, Loisance D, Groscurth $\mathrm{P}$, Turina M. Less invasive aortic valve surgery: rationale and technique. Eur J Cardiothorac Surg 1999;15:781-5.

3. Bakir I, Casselman FP, Wellens F, Jeanmart H, De Geest $\mathrm{R}$, Degrieck I, et al. Minimally invasive versus standard approach aortic valve replacement: a study in 506 patients. Ann Thorac Surg 2006;81:1599-604.

4. Bakir I, Casselman FP, Onan B, Van Praet F, Vermeulen Y, Degrieck I. Does a minimally invasive approach increase the incidence of patient-prosthesis mismatch in aortic valve replacement? J Heart Valve Dis 2014;23:161-7.

5. van der Merwe J, Casselman F, Stockman B, Van Praet F, Beelen R, Maene L, et al. Minimally invasive primary aortic valve surgery: the OLV Aalst experience. Ann Cardiothorac Surg 2015;4:154-9.

6. Bakir I, Casselman F, De Geest R, Wellens F, Foubert L, Degrieck I, et al. Minimally invasive aortic root replacement: a bridge too far? J Cardiovasc Surg (Torino) 2007;48:85-91.

7. Bakir I, Casselman FP, De Geest R, Wellens F, Degrieck I, Van Praet F, et al. Should minimally invasive aortic valve replacement be restricted to primary interventions? Thorac Cardiovasc Surg 2007;55:304-9.

8. Borger MA, Moustafine V, Conradi L, Knosalla C, Richter M, Merk DR, et al. A randomized multicenter trial of minimally invasive rapid deployment versus conventional full sternotomy aortic valve replacement. Ann Thorac Surg 2015;99:17-25.

9. Miceli A, Murzi M, Gilmanov D, Fugà R, Ferrarini M, Solinas $\mathrm{M}$, et al. Minimally invasive aortic valve replacement using right minithoracotomy is associated with better outcomes than ministernotomy. J Thorac Cardiovasc Surg 2014;148:133-7.

10. Miller DC, Blackstone EH, Mack MJ, Svensson LG, Kodali SK, Kapadia S, et al. Transcatheter (TAVR) versus surgical (AVR) aortic valve replacement: occurrence, hazard, risk factors, and consequences of neurologic events in the PARTNER trial. J Thorac Cardiovasc Surg 2012;143:832-43.

11. Murtuza B, Pepper JR, Stanbridge RD, Jones C, Rao C, Darzi A, et al. Minimal access aortic valve replacement: is it worth it? Ann Thorac Surg 2008;85:1121-31.

12. Kocher AA, Laufer G, Haverich A, Shrestha M, Walther T, Misfeld M, et al. One-year outcomes of the Surgical Treatment of Aortic Stenosis With a Next Generation Surgical Aortic Valve (TRITON) trial: a prospective multicenter study of rapid-deployment aortic valve replacement with the EDWARDS INTUITY Valve System. J Thorac Cardiovasc Surg 2013;145:110-5.

13. Brown ML, McKellar SH, Sundt TM, Schaff HV. Ministernotomy versus conventional sternotomy for aortic valve replacement: a systematic review and meta-analysis. J Thorac Cardiovasc Surg 2009;137:670-679.e5.

14. Lamelas J, Sarria A, Santana O, Pineda AM, Lamas GA. Outcomes of minimally invasive valve surgery versus median sternotomy in patients age 75 years or greater. Ann of Thorac Surg 2011;91:79-84.

15. Johnston DR, Roselli EE. Minimally invasive aortic valve surgery: Cleveland Clinic experience. Ann Cardiothorac Surg 2015;4:140-7.

16. Lehmann S, Merk DR, Etz CD, Seeburger J, Schroeter $\mathrm{T}$, Oberbach A, et al. Minimally invasive aortic valve replacement: the Leipzig experience. Ann Cardiothorac Surg 2015;4:49-56.

17. Gosev I, Kaneko T, McGurk S, McClure SR, Maloney A, Cohn LH. A 16-year experience in minimally invasive aortic valve replacement: context for the changing management of aortic valve disease. Innovations (Phila) 2014;9:104-10.

18. Sönmez B, Ünal M, Tansal S, Demirsoy E, Arbatli H, Yağan $\mathrm{N}$, et al. A comparative study of aortic valve surgery with limited sternotomy versus standart sternotomy. Turk Gogus Kalp Dama 1999;7;296-302.

19. Sarioğlu T, Erek E, Kinoğlu B, Aydemir NA, Asarioğlu A, Sansoy V. Alternative less invasive approach for patients with aortic valve disease and subaortic stenosis: right anterior submammarian minithoracotomy. Turk Gogus Kalp Dama 2000;8;771-3. 